\title{
Programas de desenvolvimento local na região Nordeste do Brasil: uma avaliação preliminar da "guerra físcal" 1
}

\author{
Ana Carolina da Cruz Lima ${ }^{2}$ \\ João Policarpo Rodrigues Lima ${ }^{3}$
}

\begin{abstract}
Resumo
O Governo Federal desempenhou papel fundamental no processo de desenvolvimento da economia brasileira; entretanto, com a adoção, nos anos 1990, das políticas neoliberais sugeridas por organismos internacionais, houve um esvaziamento desta intervenção, inclusive em relação à elaboração e aplicação de políticas de desenvolvimento regional. Este espaço foi gradativamente substituído por iniciativas estaduais através de seus próprios programas de desenvolvimento, baseados na concessão de incentivos fiscais relativos ao ICMS - principal imposto sobre o valor adicionado nacional. A utilização destes instrumentos se intensificou no decorrer da década de 1990 através de um fenômeno que ficou conhecido como "guerra fiscal". Este artigo analisa se há alguma influência entre a concessão de incentivos fiscais e a dinâmica da indústria de transformação e extrativa mineral na região Nordeste do Brasil. A análise dos dados referentes aos programas estaduais e da RAIS/MTE (através do cálculo do Quociente Locacional) permite indicar que há uma relação positiva - ainda que não muito significativa - com o crescimento do emprego, a interiorização e a diversificação das atividades industriais, o que pode ter contribuído para a dinâmica da região no período 1995-2005. Os dados evidenciam que estes programas não são capazes, por si só, de alterar significativamente a dinâmica econômica local, visto os incentivos não serem os únicos fatores determinantes da atratividade local. Assim, torna-se clara a necessidade da adoção de outras medidas econômicas, de caráter mais duradouro e estrutural, para estimular as áreas menos dinâmicas do país.
\end{abstract}

Palavras-chave: Políticas de Desenvolvimento Regional; ICMS; Guerra fiscal; Indústria de transformação; Emprego.

\section{Abstract \\ Local development programs in northeast Brazil: a preliminary evaluation of "fiscal war"}

The federal government has played an important role in the development of the Brazilian economy. However, due to the adoption of neoliberal policies - suggested by international organs - in the 1990's, State intervention in the economy fell substantially, particularly in relation to the planning and application of regional development policies. This area, previously controlled by the central government, has gradually been replaced by initiatives from sub national spheres of government, who started creating their own development programs based essentially on fiscal incentives related to

(1) Trabalho recebido em junho de 2008 e aprovado em maio de 2009.

(2) Doutoranda em Economia - Centro de Desenvolvimento e Planejamento Regional da Universidade Federal de Minas Gerais (Cedeplar/UFMG)/Bolsista CNPq (Conselho Nacional de Desenvolvimento Científico e Tecnológico), Belo Horizonte, MG, Brasil. E-mail: ana_carolinacl@yahoo.com.

(3) Professor do Departamento de Economia do Programa de Pós-Graduação em Economia da Universidade Federal de Pernambuco (PIMES/UFPE)/Pesquisador 1D do CNPq, Recife, PE, Brasil. E-mail: jprlima@ufpe.br. 
sales taxes. The use of these tools increased from the 1990's onwards, a phenomenon known as 'fiscal war'. The aim of this study is to examine how fiscal incentives influence the industrial sector, concerning jobs, internalization and diversification of productive chains in the northeastern region of Brazil. The locational quotient is calculated based on the RAIS/MTE data, so that the industrial specialization levels in the region can be evaluated. Analysis of the data referring to the state programs makes it possible to indicate that there is a positive relationship between the increase in job offers, internalization, diversification of industrial activities and fiscal incentives. While this relationship is not strong, the fiscal war may have contributed to the industrial dynamics of the region throughout 1995-2005. Despite this, the data show that the state programs based on fiscal and financial incentives are not capable, on their own, of significantly changing the local economical dynamics, as the incentives are not the only determining factors of investor attractiveness. Thus, the importance of adopting long-lasting and structural economic measures to stimulate less dynamic areas in the country is highlighted.

Key words: Regional development policies; Sales tax; Fiscal war; Manufacturing industry; Employment.

JEL R11.

\section{Introdução}

Nos últimos anos, a utilização de incentivos fiscais como instrumento de política econômica tem sido bastante discutida. Este fato está relacionado às transformações ocorridas na economia brasileira desde meados da década de 1980, quando as políticas de ajustamento interno e externo, adotadas no período, consolidaram a necessidade de promover reformas na economia. Estas, implementadas e consolidadas nos anos 1990, foram influenciadas por uma visão ortodoxa, como consequência das experiências bem-sucedidas das economias emergentes do sudeste asiático, e seguiram as instruções do "Consenso de Washington". A adoção destas políticas, sugeridas por organismos internacionais - Fundo Monetário Internacional e Banco Mundial -, iniciou um intenso processo de liberalização da economia brasileira, acompanhado da estabilização de preços, via Plano Real, e do esvaziamento da intervenção estatal na economia, com redução dos mecanismos de políticas de desenvolvimento regional elaborados pelo governo central.

Estes fatos deixaram praticamente a cargo apenas dos Estados a responsabilidade pela aplicação de medidas de estímulo à dinâmica econômica local. Como consequência, a disputa por investimentos produtivos entre os Estados, através da concessão de incentivos fiscais, tornou-se o principal instrumento de política de desenvolvimento, o que valorizou excessivamente o desenvolvimento local em detrimento das demandas nacionais. Este fenômeno, conhecido como guerra fiscal, se intensificou nos últimos anos, principalmente no período pós-95, o que abriu espaço para a discussão dos possíveis benefícios e/ou prejuízos que o mesmo pode trazer para os Estados em particular e para o país como um todo. 
Este tema é abordado sob diferentes perspectivas, que ora priorizam seus aspectos negativos (Varsano, 1997; Diniz, 2001; Dulci, 2002.), ora enfatizam sua utilização como alternativa à ausência de políticas nacionais de desenvolvimento regional (Prado, 1999). Mesmo com focos distintos, estas abordagens indicam que a estratégia estadual é um meio de atrair novas indústrias para auxiliar o desenvolvimento e estimular a competitividade local no cenário nacional e internacional. Por isso, naturalmente se estabelece uma relação entre o desenvolvimento de um Estado e o desempenho de seus instrumentos de política econômica, de tal forma que alguns autores consideram a utilização de incentivos fiscais elemento responsável ao menos pela manutenção das taxas de crescimento de determinados Estados (Soares et al., 2007; Rocha et al., 2006).

Assim, dada a ausência do poder central na elaboração e implementação de políticas de desenvolvimento regional no país, o objetivo deste trabalho é analisar os dados relativos às empresas incentivadas pelos programas estaduais, no que concerne ao investimento realizado, ao emprego direto gerado e à localização e finalidade do empreendimento, fornecidos pelos órgãos administradores dos respectivos programas, em conjunto com os dados da Relação Anual de Informações Sociais do Ministério do Trabalho e Emprego (RAIS/MTE). Esta análise serve para observar em que medida o aumento do emprego e dos estabelecimentos na indústria de transformação e extrativa mineral na região Nordeste foi afetado pelos programas estaduais, bem como a diversificação e a interiorização destas atividades. É importante ressaltar que o enfoque dado à indústria na política de desenvolvimento regional reside no fato de ainda haver no país a ideia de que o caminho mais rápido para o desenvolvimento é a industrialização (devido aos seus possíveis efeitos de encadeamento e também como herança dos ensinamentos da Comissão Econômica para a América Latina e o Caribe - Cepal). Desta forma, a análise das políticas de desenvolvimento regional ocorre em torno deste setor, priorizando-se, aqui, o estudo da região Nordeste, visto que "[...] esta é a região para a qual a atenção sempre se volta quando se fala em política regional no país" (Diniz, 2001, p. 15).

Na seção 1 do artigo é realizado um retrospecto da guerra fiscal no Brasil, salientando os fatores que impulsionaram a utilização destes instrumentos e seus aspectos positivos e negativos, tanto do ponto de vista estadual quanto nacional. $\mathrm{Na}$ seção 2 são destacados os principais programas estaduais de estímulo ao desenvolvimento industrial na região Nordeste do Brasil, cujos dados são analisados na seção 3. Em seguida são realizadas as conclusões do artigo.

\section{A guerra fiscal no Brasil}

Entre as décadas de 1960 e 1980, uma das principais características do sistema tributário brasileiro, visto como instrumento manejado pelas autoridades 
governamentais para viabilizar objetivos econômicos e sociais, foi a grande centralização fiscal. A União arrecadava a maior parte dos impostos e tinha poder absoluto para deliberar sobre a matéria tributária. Entretanto, no decorrer dos anos 1980, com a crise da dívida externa e as gradativas mudanças no papel do Estado, a estrutura do sistema tributário afastou-se dos pilares firmados na reforma tributária de 1964 e, em 1988, com a promulgação da Constituição Federal, os Estados e municípios obtiveram maior participação na arrecadação e aumento na base de incidência dos impostos de competência própria, o que aumentou a autonomia dos mesmos para deliberar sobre assuntos fiscais (Oliveira, 2006).

A partir deste período, o diferimento, a isenção ou mesmo a renúncia de impostos sobre o valor adicionado nacional (isto é, o Imposto Sobre Produtos Industrializados - IPI -, de competência federal, e o Imposto sobre a Circulação de Mercadorias e Serviços - ICMS -, de competência estadual), utilizados para impulsionar o desenvolvimento ou a implantação de determinadas indústrias no país/região, tornaram-se mais comuns. O ICMS, em especial, tem sido bastante utilizado com esta finalidade, devido à ausência de políticas nacionais de desenvolvimento regional. Os Estados têm utilizado cada vez mais este instrumento de política fiscal por meio da elaboração de programas estaduais de estímulo ao investimento e à indústria local, o que tem gerado disputas e controvérsias, num fenômeno que ficou conhecido como guerra fiscal. Lagemann (1995, p. 12) define esse fenômeno da seguinte forma:

[...] é um processo de competição interjurisdicional, operada pela adoção de medidas de caráter fiscal que afetam a base tributária das demais unidades de governo e dessa forma trazem vantagens e/ou desvantagens diferenciais ao bemestar dos cidadãos da territorialidade envolvida, ainda que possam estar em conflito com os interesses da nação.

A guerra fiscal tem sido uma característica dos países marcados por grandes desigualdades regionais, cuja reduzida participação do Governo Federal na economia gera dificuldades para elaborar políticas de desenvolvimento regional. Este fato exclui a visão mais simplista deste fenômeno, que deve ser visto como uma forma peculiar de política de desenvolvimento regional, responsável, em alguns casos, pela manutenção da dinâmica das economias estaduais.

No período que vai de meados dos anos 1960 até o final da década de 1980, estes programas estiveram subordinados ao governo central, que através de seu poder fiscal-financeiro e político procurava coordenar as iniciativas estaduais e inibir os conflitos inter-regionais, oriundos das disparidades existentes entre as regiões do país. A intensificação desse tipo de instrumento, principalmente a partir de 1995, está ligada a diferentes fatores, detalhados a seguir. 
Programas de desenvolvimento local na região Nordeste do Brasil: uma avaliação preliminar da "guerra fiscal"

\subsection{Condicionantes para a intensificação da guerra fiscal}

O conflito fiscal entre Estados é resultado de certas condições políticas e econômicas que emergiram desde os anos 1980, a saber:

i) Descentralização política e institucional: a Constituição Federal de 1988 impulsionou o processo de descentralização, iniciado em fins da década de 1970, devido a fragilização do poder regulatório do Governo Federal, traduzido no deslocamento de poder em favor dos Estados e municípios. Ao mesmo tempo, alterou o quadro tributário no âmbito da Federação, atribuindo aos Estados o poder de fixar por leis próprias as alíquotas de ICMS sobre operações internas, sendo este imposto responsável por importante parcela da receita estadual, tornando-os agentes mais dinâmicos na alocação do investimento público (arcabouço jurídico);

ii) A mudança no papel do Estado: o início do processo de liberalização da economia nacional foi acompanhado do esvaziamento do Estado, com o abandono das políticas e dos instrumentos de coordenação regional, traduzido por uma postura contrária às políticas ativas de caráter regional. Este fato, associado à expansão do desemprego no setor industrial, conduziu a uma retomada de iniciativas dos sistemas políticos regionais, que preencheram rapidamente o espaço deixado pelo Governo Federal (alicerce político);

iii) A retomada dos investimentos privados: a abertura da economia estimulou a intensificação da guerra fiscal, pois atraiu fluxo crescente de capitais internacionais em busca de oportunidades no país (arcabouço econômico).

Outro fator de estímulo à guerra fiscal está relacionado à estrutura de tributação do principal imposto sobre o valor adicionado nacional, especialmente em relação ao comércio interestadual. Em primeiro lugar, a competência sobre o ICMS é dos governos estaduais, o que retira do poder central qualquer tentativa de regulação. Em segundo, o "Princípio da Origem" na formulação do ICMS garante que a arrecadação de cada Estado seja definida pela produção realizada em seu território, independente do pagamento efetivo do imposto por seus habitantes. A alíquota do ICMS aplicável às transações interestaduais é positiva e inferior à alíquota aplicável em uma operação interna com a mesma mercadoria, de modo que a receita referente àquela transação se reparta entre as unidades de origem e destino. Nestas condições, o resultado de um ato de investimento objeto do incentivo é uma ampliação imediata da arrecadação tributária do governo que o concede, mesmo quando a produção é voltada para outro mercado que não o seu. O "Princípio da Origem" é condição necessária para que os Estados possam negociar com as empresas as condições de recolhimento do imposto, dado que ele garante apropriação da receita gerada pelo Estado que concede o incentivo (visto ele ser o destinatário legal da arrecadação), mesmo no caso extremo em que toda a produção seja exportada para outros Estados. Esta sistemática de tributação foi 
estabelecida para assegurar uma participação adequada na receita total dos Estados deficitários no comércio interestadual, em geral aos menos desenvolvidos do país.

Salienta-se que alguns dispositivos foram criados para inibir a guerra fiscal e, como destaca Varsano (1997), desde a década de 1970 existe no país legislação suficiente para coibi-la (Lei Complementar n. 24 de 1975). Entretanto, as normas referentes à concessão de incentivos não foram consolidadas e os preceitos de ordem legal existentes sobre o assunto foram gerados de forma fragmentada por meio de convênios no âmbito do Conselho de Política Fazendária (Confaz). Este perdeu gradativamente sua posição normatizadora, à medida que o Governo Federal diminuía sua participação na economia.

$\mathrm{Na}$ origem deste processo - intensificação da guerra fiscal - estão as disparidades regionais e as limitações de recursos internos para investir em projetos capazes de diminuir estas dificuldades. Por este motivo, pode ser vantajoso para cada Estado, individualmente, entrar nesse jogo, principalmente se suas chances de atrair investimentos sem incentivos são pequenas. E ainda:

[...] numa situação em que o Governo Central de um país com altas disparidades abandone qualquer preocupação por políticas integradas de desenvolvimento regional, fica politicamente legitimada a pretensão dos governos estaduais, principalmente daqueles relativamente mais atrasados economicamente, em operar políticas deste formato (Prado, 1999, p. 35).

Assim, do ponto de vista da economia e da sociedade locais, a concessão de incentivos fiscais é justificada, da mesma forma que as suposições simplistas sobre a guerra fiscal são afastadas, permitindo que esta surja como uma alternativa lógica de política de desenvolvimento regional.

\subsection{A guerra fiscal como política de desenvolvimento regional}

As economias estaduais têm utilizado isenções tributárias para estimular o crescimento da indústria local e superar seu respectivo atraso relativo. Estas políticas procuram interferir no processo de decisão locacional privado e, por isso, algumas lideranças estaduais têm defendido que os benefícios fiscais são determinantes básicos deste processo - sendo este um dos argumentos utilizados para justificar a guerra fiscal. Entretanto, a decisão de inversão está subordinada a determinantes de natureza mais ampla, como as condições de infraestrutura logística, a estrutura de custos, a disponibilidade de mão-de-obra qualificada, a qualidade dos serviços públicos, o acesso a mercados consumidores e fornecedores, etc.; ou seja, a decisão locacional das empresas está ligada principalmente às tendências de longo prazo (fatores sistêmicos).

Assim, as empresas buscam um perfil alocativo ótimo, com áreas de equivalência possuidoras da infraestrutura necessária ao seu funcionamento, e só 
depois procuram, entre estas, a localidade onde são oferecidos os incentivos mais vantajosos. Qualquer alteração neste perfil alocativo envolve um custo adicional (de afastamento) que deve ser coberto pelos incentivos fiscais. As decisões de localização valem-se da oferta de incentivos fiscais sem ignorar os demais fatores.

Seria, então, a concessão de incentivos um instrumento incapaz de aumentar o investimento agregado? Não necessariamente, visto que os incentivos fiscais podem: a) ampliar o volume de inversão, ainda que por vezes possam ser redundantes, principalmente num contexto de abertura econômica e afluxo de IED; b) reduzir os custos de inversão no país, o que pode alterar decisões de inversão externa, que, na sua ausência, poderiam buscar outros países da América Latina; e c) constituir uma política de Second Best para o tratamento das questões regionais.

Do ponto de vista estadual, o resultado do investimento objeto do incentivo é uma ampliação imediata da arrecadação tributária do governo que o concede. A base orçamentária em que o incentivo se apoia não é previamente dada, o que concede ao governo um poderoso instrumento de renúncia da receita futura gerada pelo projeto beneficiado, sem afetar seu nível de receita corrente. As novas plantas devem gerar efeitos indutores sobre a economia local, como a atração de investimentos complementares, a criação de novos postos de trabalho, a descentralização da atividade produtiva e a expansão do nível de renda local. Desde que o governo não subsidie estes investimentos complementares, e contando com o sucesso do empreendimento incentivado, deve ocorrer um aumento da arrecadação corrente e, após o período de concessão, a situação fiscal estará provavelmente melhorada. Atrelada a este fato está a questão política: se a concessão de incentivos, ao menos na visão do governante estadual, traz benefícios para o Estado (e, além disso, tem impactos positivos para seu projeto político pessoal), o benefício certamente será concedido, a despeito dos interesses nacionais.

A concessão de incentivos também pode auxiliar no processo de distribuição da atividade produtiva, quando combinada a outras medidas de desenvolvimento regional, uma vez que ela pode estimular a instalação de novas plantas em regiões com menor dinamismo econômico. Para tanto este deve ser um mecanismo seletivo, destinado a estimular vantagens comparativas locais e de caráter temporário, pois a generalização do mesmo reduz sua eficácia. Em geral, os resultados da guerra fiscal dependerão da natureza dos setores econômicos envolvidos e da dimensão relativa das empresas beneficiadas. 
Ana Carolina da Cruz Lima / João Policarpo Rodrigues Lima

\subsection{Aspectos negativos da guerra fiscal}

A guerra fiscal pode ser considerada a expressão mais evidente das políticas autônomas de desenvolvimento. A questão central para a utilização destes instrumentos deve considerar até que ponto estas políticas são viáveis e eficientes para o desenvolvimento local, ou seja, em que medida as mesmas influenciam o fluxo total de novos investimentos na localidade e sua distribuição espacial.

Alguns autores defendem que a guerra fiscal, apesar de preencher uma lacuna deixada pelo Governo Central, não traz benefícios para o país como um todo. Segundo Varsano (1997) e Dulci (2002), a hipótese necessária para que os resultados da guerra fiscal sejam positivos está relacionada à confrontação dos benefícios esperados da inversão incentivada com o custo necessário para obter o afastamento do empreendimento de sua localização ótima, determinada a partir da avaliação dos fatores sistêmicos e das condições tributárias locais. Como os primeiros são dados ex-ante ao processo de tomada de decisão, além de serem fixos no curto prazo, resta aos Estados concederem benefícios fiscais para as empresas, de tal forma que estas aceitem investir em uma localidade sub-ótima. Os incentivos devem cobrir os custos de afastamento e compensar os riscos envolvidos na operação; logo, quanto mais distante uma localidade estiver da alocação ótima da empresa, maior o custo fiscal envolvido na concessão do benefício. O benefício só seria concedido se a avaliação custo/benefício fosse positiva. Todavia, este tipo de avaliação, mesmo quando realizada com rigor técnico, pode não corresponder às preferências alocativas privadas, visto que estas não são voluntariamente reveladas, o que potencializa os custos envolvidos nos programas, pois as empresas estimulam a competição entre os Estados, dando origem a um leilão de incentivos.

Dada a ausência da ação reguladora do poder central, a eficiência dos instrumentos estaduais é determinada basicamente por três fatores interdependentes: i) a dinâmica orçamentária estadual; ii) o ciclo político e a dinâmica da relação público-privado; e iii) o grau de redundância dos programas adotados (Ferreira, 2005).

As condições orçamentárias e as estruturais institucionais estaduais determinam sua capacidade de execução de políticas de desenvolvimento. Quanto menos desenvolvidas estas características, mais dificuldades os Estados terão para elaborar e adotar políticas sistêmicas que estimulem o desenvolvimento de longo prazo. No caso brasileiro - em que vários Estados possuem uma situação fiscal debilitada -, há um grande estímulo para a adoção de políticas baseadas na concessão de incentivos fiscais, visto que tais políticas 
independem, em alguma medida, de seu nível de desenvolvimento atual. ${ }^{4}$ Esta é a forma que os Estados encontraram para compensar seus diferenciais de atratividade e competitividade, subindo algumas posições no ranking de preferências do setor privado. Entretanto, os resultados destas políticas são limitados, pois, em geral, são apropriados individualmente pelas empresas e não geram melhorias estruturais locais. Assim, o esforço que cada Estado terá de desempenhar é inversamente proporcional ao seu nível de desenvolvimento (quanto menos atrativo, maior o benefício concedido), o que tende a elevar o custo fiscal envolvido na realização do investimento.

Em relação ao ciclo político observa-se que mesmo nos casos de uma avaliação custo-benefício desfavorável, o incentivo fiscal pode ser concedido, pois as lideranças locais aumentariam seu prestígio por meio da atração de um novo empreendimento. Ou seja, a necessidade de obter resultados relevantes no período de governo cria um forte incentivo à utilização de incentivos fiscais, cujos resultados independem da situação estrutural da economia. Além disso, dada a incerteza relacionada à duração deste ciclo, os setores privados exigirão benefícios mais duradouros, que não sejam interrompidos com uma possível troca de governo. Em outras palavras, além de cobrir o custo de afastamento do investimento, o Estado também precisa cobrir o risco de ruptura do ciclo político - mais um fator que eleva o custo fiscal destes instrumentos.

Como destacado, a concessão de incentivos fiscais baseia-se na hipótese de que eles têm influência sobre o processo de alocação dos investimentos privados. Entretanto, devido à assimetria de informações entre setores públicos e privados e à dinâmica do processo de concorrência entre Estados, parte dos benefícios concedidos é redundante, ou seja, uma parte dos incentivos destina-se à empresas que se instalariam na localidade independente de sua existência. $\mathrm{O}$ grau de redundância seria (na definição mais simples possível), então, o percentual de incentivos fiscais que destinam-se a investimentos que já decidiram se instalar no Estado em relação ao total de incentivos envolvidos no programa. Segundo Wells Jr. e Allen (2001, p. 22):

If tax incentives are given only to investors who would not otherwise have come, and are exactly the amount required to attract them, then there is no revenue loss from the incentives-zero redundancy. On the other hand, if incentives go to investors who would have come anyway, there is redundancy and the foregone revenue from those redundant incentives represents a cost to the treasure.

Esta definição de redundância implica que todo programa estadual possui determinado grau de redundância, praticamente impossível de ser medido, dada a

(4) A capacidade de conceder incentivos se torna, em certo grau, independente do nível de desenvolvimento local devido às peculiaridades da estrutura do sistema tributário nacional relacionadas na subseção 1.1 do artigo.

Economia e Sociedade, Campinas, v. 19, n. 3 (40), p. 557-588, dez. 2010. 
dificuldade em calcular o percentual ótimo de incentivo para atrair o investimento. O grau de redundância fornece uma estimativa dos custos dos incentivos, porém seu cálculo não é trivial. ${ }^{5}$ É preciso destacar que, apesar da redundância não ser totalmente eliminada, visto que é estrutural, ela pode ser afetada por alguns fatores como, por exemplo, a abrangência setorial e espacial dos programas estaduais. A discricionariedade ou seletividade dos programas, que depende das decisões das comissões responsáveis pela concessão dos benefícios, pode evitar que sejam concedidos incentivos para empresas de setores já consolidados no Estado e em áreas mais dinâmicas (é, em última instância, uma tentativa de minimizar custos). Se os programas são indiferentes em relação a estes fatores, é mais provável que os benefícios sejam concedidos para investimentos já determinados, o que diminui sua eficácia e eleva o grau de redundância e o custo fiscal.

Analisando o caso da Indonésia, Wells Jr. e Allen (2001) evidenciam que os resultados suportam os argumentos contra os incentivos, cuja eliminação, em meados da década de 1980, não causou declínio na taxa de IED no país, mesmo quando os países vizinhos mantiveram seus programas (os resultados dos testes não foram estatisticamente diferentes de zero). Seus cálculos demonstram que o custo total da concessão de incentivos fiscais na Indonésia excedeu seus benefícios, o que parece corroborar o fato de que os incentivos não são determinantes essenciais da localização dos investimentos, pelo menos no caso em que o país (a localidade) possui taxas de crescimento mais atrativas do que seus vizinhos.

Além disso, em geral os Estados mais desenvolvidos têm melhores condições locacionais e financeiras e, por este motivo, são os principais vencedores da guerra fiscal, o que provavelmente agrava as disparidades regionais e aumenta as tensões entre os Estados. Possivelmente também pode haver um impacto social das renúncias fiscais, visto que os Estados que as concedem nem sempre estão em condições de fazê-lo sem sacrificar sua população - isto é, enquanto redução dos investimentos em saúde, educação, moradia, etc.

Por fim, a generalização dos benefícios fiscais provoca a redução de seu poder de estímulo, que depende dos diferenciais de tributação, o que reduz o peso da tributação nas decisões locacionais dos investimentos. Além disso, programas mais amplos estão sendo substituídos por operações, cuja finalidade é atender a projetos específicos de grande porte, e assim os mesmos assumem a forma de pretensos programas de desenvolvimento regional, quando na realidade maximizam o custo fiscal.

(5) Wells Jr. e Allen (2001) demonstram que há formas equivalentes para calcular estes custos, uma vez que os incentivos redundantes funcionam como subsídios para a iniciativa privada. 
Considerados estes aspectos negativos, a guerra fiscal não deveria desaparecer? Deveria, não fosse a natureza peculiar do fenômeno (como ficou dito), que decorre, principalmente, da dificuldade em mensurar o impacto sobre a arrecadação estadual oriunda dos incentivos fiscais (prado, 1999). Algumas medidas para minimizar os estímulos à guerra fiscal poderiam ser tomadas, como a reforma do sistema tributário (unificação da legislação nacional do imposto sobre valor adicionado e implantação do princípio do destino no comércio interestadual). Isto não eliminaria a disputa, mas funcionaria como uma forte restrição à eficácia dos incentivos do ICMS. As principais dificuldades para a implantação destas medidas residem na esfera política, pois os Estados exportadores líquidos neste comércio - os mais desenvolvidos e com maior poder econômico e político - teriam uma redução na arrecadação e, por isto, resistiriam às mudanças.

\section{Programas estaduais de desenvolvimento local}

O esvaziamento do papel do Estado na economia brasileira a partir da década de 1990, traduzido na insuficiência de instrumentos de planejamento regional a nível federal, estimulou a elaboração de programas de desenvolvimento por parte dos governos estaduais, como forma de impulsionar a dinâmica econômica local. Estes programas, baseados principalmente na concessão de incentivos fiscais, têm como objetivo interferir na alocação do investimento privado, atraindo para o Estado empreendimentos que não o fariam caso o incentivo não existisse (esta é a premissa dos programas). Os principais programas estaduais dos nove Estados que compõem a região Nordeste, de acordo com as respectivas legislações estaduais, são:

- Sistema de Apoio à Indústria e ao Comércio Exterior do Estado do Maranhão - SINCOEX;

- Lei de Incentivos Fiscais do Piauí - Lei n 4.859, de 27 de Agosto de 1996;

- Fundo de Desenvolvimento Industrial do Ceará - FDI;

- Programa de Apoio ao Desenvolvimento Industrial do Rio Grande do Norte - PROADI;

- Fundo de Apoio ao Desenvolvimento Industrial da Paraíba - FAIN;

- Programa de Desenvolvimento do Estado de Pernambuco - PRODEPE;

- Programa de Desenvolvimento Integrado do Estado de Alagoas PRODESIN;

- Programa Sergipano de Desenvolvimento Industrial - PSDI;

- Programa de Desenvolvimento Industrial e de integração Econômica do Estado da Bahia - DESENVOLVE. 
De forma geral, estes programas possuem algumas semelhanças, dentre as quais destacam-se a prioridade na concessão de incentivo dada aos projetos de investimento que utilizem matérias-primas e insumos locais, explorem potenciais produtivos do Estado, desenvolvam atividades com alto teor tecnológico e tenham alto poder germinativo em relação ao emprego ${ }^{6}$ - além de considerarem o volume de investimento a ser realizado.

A meta dos programas estaduais é estimular a dinâmica local, através do crédito presumido, do diferimento e/ou financiamento do ICMS devido (exceto no caso do PI, que concede a dispensa do pagamento do ICMS), em setores já consolidados no Estado e em setores sem tradição local. $\mathrm{O}$ intuito principal é diversificar as cadeias produtivas, aumentar a arrecadação futura deste imposto, consolidar aglomerações produtivas existentes em seus territórios e gerar emprego e renda, de forma que o crescimento futuro da economia se torne menos dependente da concessão destes incentivos.

Os benefícios são concedidos a projetos de implantação, ampliação, relocalização, modernização e revitalização de empreendimentos industriais e agroindustriais, bem como ao desenvolvimento de novos produtos. No caso do MA, também são incentivadas empresas voltadas ao comércio exterior e, em PE, importadores atacadistas e centrais de distribuição. O percentual do ICMS financiado gira em torno de $75 \%$, porém pode chegar à totalidade do imposto em determinadas circunstâncias e Estados. Por exemplo, no PI e em AL, os primeiros anos do benefício correspondem a $100 \%$ do ICMS, que vai sendo reduzido gradativamente. Os incentivos em PE e PB também podem chegar a $100 \%$ do ICMS, caso os empreendimentos sejam considerados prioritários ou se localizem em determinadas regiões do Estado.

Os Estados que têm menor prazo de fruição dos benefícios são CE, RN, SE e PE (10 anos nos três primeiros casos e 12 no último). Entretanto, nestes Estados é possível solicitar prorrogação deste prazo que pode chegar a, respectivamente, 15, 20, 20 e 18 anos. Em seguida vêm os prazos de BA (12 anos), MA (12 anos e 6 meses), PI, PB e AL (15 anos em cada caso). O prazo de carência é de 3 anos na maioria dos Estados, com exceção de AL e SE (2 anos). PE e PI não fazem referência a este prazo.

Em relação à interiorização da indústria, os Estados que deixam mais claro em seus programas o aumento do benefício para empreendimentos que se localizem fora da região mais desenvolvida do Estado são PB, RN, CE, PI e SE. O programa pernambucano diz que são financiados $100 \%$ do ICMS de empreendimentos localizados em áreas consideradas prioritárias para o Estado,

(6) O critério varia entre os Estados; por exemplo, o Maranhão prioriza projetos de investimento que gerem 100 ou mais empregos diretos, o Ceará, 350, e a Paraíba 500. 
mas não deixa claro quais seriam estas áreas. MA e BA não definem percentuais específicos para empreendimentos localizados no interior.

Os encargos financeiros não são citados em muitos programas, como é o caso de PE, PI, AL e SE. Nos demais, os encargos não ultrapassam $12 \%$ a.a. O mesmo pode ser observado em relação às garantias dos financiamentos (não mencionadas ou limitando-se a garantias fidejussórias ou aval dos sócios).

Nos casos da PB, AL e SE é explícito o apoio à iniciativa privada também no que diz respeito à infraestrutura necessária ao funcionamento dos estabelecimentos, como a execução de obras em terrenos nos quais os empreendimentos serão implantados, a cessão de galpões e terrenos, etc.

Vale lembrar que a regra geral, em todos os programas, é que o benefício não pode diminuir a arrecadação presente do ICMS.

Em geral, também, os programas estaduais têm características similares e parecem seguir a mesma lógica de criação de postos de trabalho, adensamento das cadeias produtivas e interiorização da indústria. Entretanto, não se pode deixar de destacar que incentivos físcais não são os únicos fatores que influenciam as decisões de investimento da iniciativa privada. Estes programas não devem, em princípio, ser considerados a melhor opção de política de desenvolvimento local, apesar de suas constantes reformulações, uma vez que é preciso adotar medidas mais amplas, como melhorias no sistema educacional e de qualificação do trabalhador, a fim de estimular a competitividade e aumentar os fatores de atratividade local.

\section{Análise dos programas estaduais de incentivos fiscais}

O objetivo desta seção é analisar, em alguma medida, os impactos dos mecanismos estaduais de incentivo à industrialização existentes no Nordeste para as economias locais no período 1995-2005, em termos de emprego gerado, investimento realizado, interiorização da indústria e adensamento das cadeias produtivas. Para tanto, são analisados dados referentes aos respectivos programas, fornecidos por seus órgãos administradores, em relação às empresas incentivadas. ${ }^{7}$ É preciso salientar que as informações sobre o investimento e o emprego referemse àquelas declaradas nos projetos beneficiados pelos programas, e não ao que foi efetivamente realizado. Os Estados vêm trabalhando no sentido de fornecer dados mais precisos, pois há uma preocupação em averiguar a situação dos projetos incentivados para, através do desenvolvimento de sistemas de acompanhamento, avaliar a aplicabilidade de seus programas. Contudo, apesar do esforço realizado,

(7) A classificação setorial dos programas obedece a normas específicas de cada Estado e, por este motivo, a comparação direta destes programas deve ser cautelosa. 
não foram fornecidos dados relativos aos programas dos Estados do MA, AL e BA (que não puderam ser analisados).

Para observar se as mudanças ocorridas no cenário local estão relacionadas à política industrial implementada pelos Estados foram utilizados dados da RAIS/MTE, especialmente sobre o emprego e o número de estabelecimentos industriais nos municípios nordestinos, por setor da indústria de transformação e extrativa mineral, em 1995 e 2005. A ideia subjacente é que estes dados refletem, parcialmente, os efeitos destas políticas sobre a economia local, visto que um dos requisitos para receber os incentivos é estimular a geração direta de emprego. Assim, pode-se supor que determinada parcela do emprego industrial nos últimos anos foi estimulada pelos programas estaduais, à medida que estes se intensificavam e novos instrumentos foram desenvolvidos.

\subsection{Metodologia}

As políticas de incentivos fiscais têm diversos impactos sobre os Estados que as concedem: não apenas são criadas novas oportunidades de investimento e emprego, mas também a arrecadação estadual é afetada, além de prováveis custos envolvidos nos programas como a realização de obras de infraestrutura. A mensuração de seus impactos é tarefa complexa, pois envolve uma série de fatores que não são facilmente comparados (Prado, 2000). Para o objetivo do presente trabalho, que é analisar se existe alguma influência entre a política de incentivos e a dinâmica da indústria de transformação e extrativa mineral, foi utilizado, em parte, instrumental metodológico descrito por Soares et al. (2007).

Em primeiro lugar, para avaliar em que medida a indústria cresceu nos Estados da região Nordeste foram considerados dados relativos ao número de estabelecimentos industriais em atividade na região. Após a constatação de aumento ou redução nesta quantidade, foi calculado, para verificar se houve mudanças no perfil industrial dos Estados e, consequentemente, da região, o Quociente Locacional $(Q L)$, a partir de informações da RAIS/MTE sobre o emprego, dado pela seguinte expressão:

$$
Q L_{i j}=\frac{\frac{E_{i j}}{E_{j}}}{\frac{E_{i e}}{E_{e}}}
$$

Onde $\quad E_{i j}=$ emprego do setor $i$ no município $j$;

$E_{j}=$ emprego total no município $j$;

$E_{i e}=$ emprego do setor $i$ no Estado;

$E_{e}=$ emprego total no Estado; 
Programas de desenvolvimento local na região Nordeste do Brasil: uma avaliação preliminar da "guerra fiscal"

$e=$ Estados nordestinos: Piauí, Ceará, Rio Grande do Norte, Paraíba, Pernambuco e Sergipe;

$j=$ municípios nordestinos dos Estados analisados; $e$

$i=$ setores da indústria de transformação e extrativa mineral: extrativa mineral; minerais não-metálicos; metalúrgica; mecânica; material elétrico e de comunicações; material de transporte; madeira e mobiliário; papel e gráfica; borracha, couro e fumo; química; têxtil; calçados; alimentos e bebidas.

O $Q L$ mede a concentração de determinada atividade econômica (setor) em uma área, tomando como referência a distribuição desta atividade num espaço geográfico mais abrangente, no qual a área em questão está inserida. Através de seu cálculo será possível identificar os setores em que cada região concentra sua economia. Este índice pode ser maior, menor ou igual a 1 (um). Se $Q L>1$, significa que o setor analisado é relativamente mais importante em termos de emprego para o município do que para o Estado ao qual pertence. Logo, o município pode ser classificado como especializado neste setor. Se $Q L<1$, significa que o setor analisado é relativamente menos importante em termos de emprego para o município do que para o Estado ao qual pertence. Logo, o município é classificado como não-especializado neste setor. O cálculo deste índice permitirá avaliar se o número de municípios especializados nos Estados aumentou ou diminuiu no período. Além disso, o $Q L$ pode ser observado para as mesorregiões estaduais, sendo esta uma forma de avaliar, ao final, em que medida os programas estaduais auxiliaram na interiorização da indústria.

A principal fonte de dados é a RAIS/MTE, visto que a análise realizada refere-se ao emprego formal industrial. Estes dados estão sintetizados nas Tabelas A.1, A.2 e A.3 do apêndice e as informações destacadas nas próximas subseções também podem ser visualizadas em tais tabelas.

\subsection{Análise dos dados}

\subsubsection{Piauí}

No período 1994-2006, de acordo com dados fornecidos pela Secretaria da Fazenda (SEFAZ) e pela Secretaria do Planejamento (SEPLAN) do Estado do Piauí, por intermédio de sua Comissão de Incentivos Fiscais (CIF), 410 empresas foram incentivadas e geraram cerca de 28.794 empregos diretos. ${ }^{8}$ Os investimentos realizados no âmbito da CIF não ocorreram de forma contínua e apenas os setores de produtos alimentícios e de minerais não-metálicos receberam incentivos de forma ininterrupta, sendo este último o principal receptor dos

(8) Os dados foram fornecidos por produto fabricado. Para facilitar a análise, os mesmos foram agrupados de acordo com a Classificação Nacional de Atividades Econômicas (CNAE).

Economia e Sociedade, Campinas, v. 19, n. 3 (40), p. 557-588, dez. 2010. 
investimentos realizados em todo o período (cerca de 93\%). Do total de projetos incentivados, $78 \%$ tinham por finalidade a implantação de novas plantas industriais; $12 \%$ a revitalização de empreendimentos e o desenvolvimento de novos produtos; $8 \%$ a ampliação de empreendimentos já existentes; e 2\% tinham outras finalidades (decretos e prorrogações). Em relação à localização, cerca de $55 \%$ dos projetos incentivados foram realizados na capital e $45 \%$ no interior, sendo que em 1997, 1999 e 2006 o percentual de empresas incentivadas no interior foi mais alto. Entre 1995 e 1997, apenas 26 empresas foram incentivadas, fato que deve estar ligado à reestruturação da legislação estadual referente aos incentivos fiscais neste período. Apenas a partir de 1998, a quantidade anual de empresas incentivadas foi superior a 25, com expressivos 72 projetos incentivados em 2003. Com exceção deste ano, os demais mantiveram-se dentro de determinado patamar, num intervalo entre 30 e 40 projetos por ano. Setorialmente, os projetos incentivados concentraram-se nos gêneros tradicionais da indústria, sendo 32,4\% em produtos alimentícios, 11,2\% em produtos minerais não-metálicos e 6,8\% em produtos de limpeza e higiene pessoal. O emprego direto gerado pelos empreendimentos incentivados foi mais expressivo em 1994, 2000 e 2003, e a média de postos de trabalho gerados no período 1994-2006 foi 2.215. A maior parcela do emprego gerado coube aos setores de produtos alimentícios $(29,1 \%)$, minerais não-metálicos $(11,8 \%)$, têxteis $(11,5 \%)$ e bebidas $(4,6 \%)$.

De acordo com os dados da RAIS/MTE, o número de estabelecimentos industriais em atividade no PI cresceu, entre 1995 e 2005, em todos os setores da indústria local, com destaque para os setores de minerais não-metálicos, materiais elétricos e de comunicações e calçados. O emprego industrial caiu nos setores extrativos minerais, borracha, couro e fumo e têxteis, e cresceu nos demais, especialmente nas indústrias mecânicas e de materiais de transporte (todavia, estes ainda representam apenas $4 \%$ do emprego industrial). Os setores de minerais nãometálicos e de produtos alimentícios e bebidas também tiveram taxas bastante positivas.

O cálculo do $Q L$ para os municípios piauienses identificou um aumento no número de municípios especializados para o total da indústria (79 para 113), principalmente nos setores de calçados e minerais não-metálicos. Os setores de materiais de transporte, borracha, couro e fumo e têxteis sofreram reduções neste quesito. Em relação à distribuição espacial da indústria, o número de municípios especializados cresceu em todas as mesorregiões do Estado, exceto no Sudeste Piauiense (região de Fronteiras, Oeiras, Picos e Pio IX, municípios que receberam cerca de $12 \%$ dos projetos incentivados). O Norte e o Sudoeste Piauiense, que abrigam os municípios de Luís Correia, Parnaíba, Corrente e Floriano (8,3\% dos projetos incentivados instalaram-se nestes municípios), possuem o maior número de municípios especializados. Ou seja, no caso do PI, o número de municípios 
especializados cresceu nas regiões do Estado em que já há certa dinâmica industrial, mesmo quando não pertencentes à área de influência da capital do Estado.

\subsubsection{Ceará}

Os dados relativos ao FDI, fornecidos pela Secretaria de Desenvolvimento Econômico do Ceará (SDE), demonstram que, no período 1994-2006, 1.111 empresas foram incentivadas e geraram 211.229 empregos diretos no Estado. Os setores incentivados que mais receberam investimentos no período foram os de refino de petróleo e químicos (cerca de $41 \%$ ), seguidos dos setores de energia eólica e elétrica (11\%), têxteis e vestuário $(9,3 \%)$. O setor de calçados foi responsável por $2,8 \%$ do investimento realizado. Do total de projetos incentivados, 91\% tinham por finalidade a implantação de novos empreendimentos industriais, $4 \%$ e $3 \%$ a ampliação e modernização, respectivamente, de empreendimentos já existentes, e 2\% outras finalidades (relocalização e comercialização). Entre 1994 e 2006, 49\% dos empreendimentos incentivados localizavam-se na $\mathrm{RMF}^{9}$ (exceto na capital), $26 \%$ no interior do Estado, 13\% nas chamadas cidades médias (Barbalha, Crato, Iguatu, Juazeiro do Norte, Limoeiro do Norte, Morada Nova, Russas e Sobral), 9\% em Fortaleza e 3\% em outras regiões. Em relação ao número de empresas incentivadas, houve um aumento significativo do mesmo entre $1994 \mathrm{e}$ 1998 (de 29 para 161), embora nos anos mais recentes o número de empresas incentivadas venha caindo, ficando bem abaixo da média do período (85). Os setores com maior número de empresas incentivadas foram os de produtos alimentícios (15,8\%), vestuário (13\%), calçados (12\%), metal-mecânica (10\%) e químico $(7,7 \%)$. Os setores de refino de petróleo e de energia eólica e elétrica, apesar de representarem boa parte dos investimentos realizados no âmbito do FDI, figuram com apenas 2,5\% do total de projetos incentivados, ou seja, poucos projetos foram incentivados nestes setores, ainda que estes estejam relacionados a grandes plantas industriais. O emprego direto gerado pelos empreendimentos incentivados acompanhou o comportamento da quantidade de empresas incentivadas: cresceu bastante entre 1994 e 1998 (de 2.816 para 35.534), recuou em 1999 e 2000, recuperou-se entre 2001 e 2003, com expressivo aumento neste último ano e, entretanto, vem caindo desde então. A média de postos de trabalho gerados no período 1994-2006 foi 16.248. Os setores que mais geraram emprego foram: calçados (20\%), vestuário (18\%), produtos alimentícios (15\%), metalmecânico $(8 \%)$ e têxteis $(6 \%)$.

A análise dos dados da RAIS/MTE mostra que o número de estabelecimentos industriais em atividade no $\mathrm{CE}$ cresceu em todos os setores da indústria entre 1995 e 2005. Destaca-se o desempenho da indústria de calçados,

(9) Região Metropolitana de Fortaleza.

Economia e Sociedade, Campinas, v. 19, n. 3 (40), p. 557-588, dez. 2010. 
que mais que duplicou o número de estabelecimentos industriais, fato que pode estar relacionado à política de incentivos fiscais estaduais, já que este foi o terceiro setor em quantidade de projetos incentivados. Este fato é reforçado pelo bom desempenho das indústrias de produtos alimentícios, têxteis, metalúrgicas, mecânicas e químicas, que também tiveram parcela significativa de seus empreendimentos beneficiados no período (aproximadamente 57\% do total de empresas incentivadas pelo FDI). O emprego industrial caiu apenas nos setores extrativos minerais, e cresceu especialmente nos setores de calçados, materiais de transporte, borracha e mecânicos, sendo mais um fato que corrobora a contribuição da política de incentivos estaduais, visto que dois destes setores (calçados e mecânico) figuram entre aqueles que mais geraram empregos diretos nos âmbito do FDI.

O cálculo do $Q L$ para os municípios cearenses identificou um aumento no número de municípios especializados em praticamente todos os setores da indústria, exceto no setor têxtil; ou seja, a produção deste setor tornou-se mais concentrada, provavelmente na RMF, dado o estímulo existente, via FDI, às empresas que pretendam se instalar próximas a Arranjos Produtivos Locais (APLs). No setor de calçados, o número de municípios especializados praticamente quadruplicou (subiu de 6 para 23), seguido dos setores metalúrgicos e de materiais de transporte. Em 2005, do total de municípios analisados, 83,7\% eram especializados em gêneros tradicionais da indústria e 16,3\% em gêneros dinâmicos (aumento de 2,5 pontos percentuais em relação a 1995). No caso do CE, a divisão regional utilizada para avaliar a distribuição espacial da indústria foi estabelecida pela SDE, de acordo com a localização dos empreendimentos incentivados pelo FDI. O número de municípios especializados manteve-se constante nas regiões do Porto do Pecém, nas cidades médias e na RMF, não por falta de dinamismo, muito pelo contrário; além de já contarem com a totalidade de seus municípios especializados em determinados setores, em alguns casos, esta especialização foi intensificada, como, por exemplo, o aumento no número de municípios especializados na produção mecânica na RMF (de 1 para 4). No interior do Estado cresceu o número de municípios especializados.

\subsubsection{Rio Grande do Norte}

Os dados relativos ao Proadi, fornecidos pela Coordenação de Desenvolvimento Industrial da Secretaria de Desenvolvimento Econômico (Sedec/Codit), evidenciam que 190 empresas foram incentivadas pelo programa e 44.929 empregos diretos foram gerados, no período $1986 / 2006 .{ }^{10}$ Setorialmente, os projetos incentivados concentraram-se nos gêneros tradicionais da indústria, sendo $65,6 \%$ em produtos têxteis e confecções, $14 \%$ em produtos alimentícios e

(10) O número de empresas incentivadas foi mais expressivo nos anos de 1998 e 2006. 
4\% em produtos minerais. Em relação ao emprego direto gerado pelo programa, até o início de 2000, o número de postos gerados por ano oscilava bastante; entretanto, a partir de 2003, apesar de não ter alcançado os patamares de 1998 e 2000 (mais de 6 mil postos), o emprego gerado passou a mostrar uma tendência crescente. Entre 2003 e 2006, aproximadamente 57\% das indústrias implantadas por intermédio do Proadi localizavam-se no interior, sendo os municípios de Mossoró e São José do Mipibu os maiores beneficiados. Foram gerados 3.816 postos de trabalho diretos no interior do Estado e os investimentos realizados chegaram a somar $\mathrm{R} \$ 144,7$ milhões.

Entre 1995 e 2005, o número de estabelecimentos industriais em atividade no Estado cresceu em todos os setores da indústria local, exceto no setor de materiais de transporte. Os setores mecânicos, de materiais elétricos, metalúrgicos (gêneros dinâmicos), têxteis e minerais não-metálicos tiveram os melhores desempenhos. Dentre estes setores, apenas o de produtos têxteis figura entre os que mais receberam incentivos do Proadi. O emprego industrial caiu apenas no setor de borracha, couro e fumo, e teve desempenho bastante favorável em alguns gêneros dinâmicos (materiais elétricos e de comunicações, metalúrgica, mecânica e química), apesar destes ainda representarem pequena parcela do emprego industrial local $(9,6 \%)$, dado o perfil capital intensivo de seus investimentos. $\mathrm{O}$ setor de calçados foi o gênero tradicional com maior aumento no emprego, seguido do setor de minerais não-metálicos.

O cálculo do $Q L$ para os municípios potiguares identificou um aumento no número de municípios especializados em todos os setores, exceto no metalúrgico, isto é, apesar do crescimento do emprego e do número de estabelecimentos neste setor, sua produção tornou-se mais concentrada. A quantidade de municípios especializados nos setores de calçados e de materiais elétricos cresceu, mas o número de municípios especializados nos mesmos ainda é muito pequeno (aumentou de 3 para 9). Apesar do bom desempenho em termos de emprego e do aumento no número de municípios especializados em sua produção, apenas $17,3 \%$ dos municípios analisados são especializados nos gêneros dinâmicos da indústria. Em relação à distribuição espacial da indústria, o número de municípios especializados sofreu redução apenas no Oeste Potiguar (região do Vale do Açu e de Mossoró), e apesar dos esforços de interiorização do Proadi, a desconcentração industrial ainda ocorre de forma limitada, pelo fato dos incentivos destinados aos municípios do interior serem bastante concentrados. Por exemplo, a partir dos dados fornecidos pela Sedec/Codit, a região do Oeste Potiguar abrigou, pelo menos, 7 empreendimentos incentivados e, entretanto, estes empreendimentos estão localizados no município de Mossoró. 
Ana Carolina da Cruz Lima / João Policarpo Rodrigues Lima

\subsubsection{Paraíba}

Entre 1995 e 2005, segundo dados relativos ao FAIN fornecidos pela Companhia de Desenvolvimento da Paraíba (Cinep), 422 empresas foram incentivadas, gerando 51.508 empregos diretos. Os setores incentivados que mais receberam investimentos no período foram: têxteis $(31,9 \%)$, produtos minerais não-metálicos $(27,4 \%)$, produtos alimentícios $(9,4 \%)$ e calçados/artefatos de couro $(5,6 \%)$. Do total de projetos incentivados, $61 \%$ tinham por finalidade a implantação de novos empreendimentos industriais, $13 \%$ e 12\%, respectivamente, a revitalização e a ampliação de empreendimentos já existentes, e 13\% a relocalização de plantas industriais. As regiões que mais receberam incentivos foram João Pessoa (39\%) e Campina Grande (37\%), principais regiões econômicas do Estado. Os anos mais expressivos em relação ao número de empresas beneficiadas pelos incentivos fiscais foram 1999 e 2004 (53 e 66, respectivamente). Em 2004 e 2005, o número de empresas incentivadas mantevese constante (43) e a média do período foi de 36 projetos incentivados . Os setores que mais se beneficiaram com os incentivos fiscais do FAIN foram: minerais nãometálicos $(17,8 \%)$, produtos alimentícios $(12,8 \%)$, calçados e artefatos de couro $(12,6 \%)$, vestuário e artefatos de tecido (7,8\%), materiais plásticos $(7,8 \%)$, metalúrgicos $(7,1 \%)$ e têxteis $(6,4 \%)$. O emprego direto gerado pelos empreendimentos incentivados foi mais expressivo nos três primeiros anos analisados e não voltou a atingir, em nenhum outro ano, o nível alcançado em 1997 (no total, 9.477 postos). Entre 1998 e 2003 este número sofreu sucessivas reduções (caiu para 1.498), exceto em 1999. Em 2004 voltou a crescer e em 2006 houve um salto do número de emprego gerado (8.355), muito superior à média do período (4.292). Os setores incentivados que mais geraram emprego foram de calçados e artefatos de couro $(23,8 \%)$, têxteis $(23,8 \%)$, minerais não-metálicos $(14 \%)$, produtos alimentícios $(8,7 \%)$ e vestuário e artefatos de tecido $(6,4 \%)$.

Em relação ao número de estabelecimentos em atividade no Estado, houve um aumento em praticamente todos os setores industriais, entre 1995 e 2005, exceto no setor de materiais de transporte. Os setores que mais receberam incentivos através do FAIN (a saber, minerais não-metálicos, produtos alimentícios e bebidas, calçados e artefatos de couro, vestuário e artefatos de tecidos, materiais plásticos, metalúrgico e têxtil) tiveram bom desempenho neste quesito. As mesmas observações podem ser feitas em relação ao emprego industrial. $\mathrm{O}$ setor com aumento mais expressivo nestes dois indicadores foi o mecânico. Apenas os setores de materiais elétricos e de comunicações, assim como o de materiais de transporte, sofreram reduções no emprego industrial entre 1995 e 2005.

O cálculo do $Q L$ para os municípios paraibanos identificou um aumento no número de municípios especializados, principalmente nos setores mecânicos, 
papel e gráfica e minerais não-metálicos. Os setores de calçados, têxteis e materiais de transporte sofreram reduções. Dos municípios analisados, apenas $16,7 \%$ são especializados em gêneros dinâmicos da indústria. Em relação à distribuição espacial da indústria, o número de municípios especializados cresceu em todas as regiões do Estado, exceto nas regiões de Itabaiana e João Pessoa (visto que permaneceram constantes, sendo que no último caso todos os municípios já apresentavam alguma especialização em 1995 e assim continuaram em 2005). As regiões com melhor desempenho foram Princesa Isabel, Itaporanga, Cajazeiras, Catolé da Rocha e Monteiro - sendo que apenas esta última não pertence ao Sertão Paraibano, o que pode indicar um avanço, ainda que não muito significativo, na interiorização da indústria (estas regiões abrigam aproximadamente $19 \%$ dos municípios especializados no Estado).

\subsubsection{Pernambuco}

No período 1996-2006, de acordo com dados relativos ao Prodepe fornecidos pela Agência de Desenvolvimento de Pernambuco (ADDiper), 1.221 empresas foram incentivadas, gerando 89.995 empregos diretos no Estado. Os setores incentivados que mais receberam investimentos no período foram os de materiais plásticos $(25,3 \%)$, produtos alimentares (12,2\%), bebidas $(10,1 \%)$, químicos $(9,9 \%)$, têxteis $(7,2 \%)$ e metalúrgicos $(6,2 \%)$. Do total de projetos incentivados, 39\% destinavam-se à implantação de novas plantas industriais; $14 \%$ à ampliação de empreendimentos em atividade; $11 \%$ às centrais de distribuição; $11 \%$ a projetos de importação; $4 \%$ à revitalização, substituição de produtos e aumento da competitividade de empreendimentos industriais; $3 \%$ à modernização de estabelecimentos; e 18\% outras finalidades (migração, reenquadramento, terceirização, etc.). Em relação à distribuição espacial dos empreendimentos incentivados, 77\% tinham sede na Região Metropolitana do Recife (RMR), 8\% no Agreste, $7 \%$ na Zona da Mata e $8 \%$ no Sertão - sendo, neste último caso, $2 \%$ localizados na região do São Francisco. Os municípios que mais receberam empreendimentos incentivados foram Recife $(32,4 \%)$, Jaboatão dos Guararapes (17,9\%), Cabo de Santo Agostinho (10,1\%) e Paulista (4,7\%), todos localizados na RMR. Houve significativo aumento na quantidade de empresas incentivadas entre 1996 e 2001 (de 38 para 158 projetos), excluindo apenas o ano 2000. A partir de então, o número de empresas incentivadas sofreu algumas reduções, especialmente em 2005 (73), recuperou-se em 2006 (93), mas ainda ficou abaixo da média do período (111 empresas). Em relação à atividade econômica, 13,4\% das empresas incentivadas eram importadoras atacadistas, $10,9 \%$ centrais de distribuição e 75,7\% empresas industriais. Os incentivos concentraram-se principalmente nos setores de materiais plásticos $(11,7 \%)$, produtos alimentares $(10,7 \%)$, minerais não-metálicos $(9,5 \%)$ e bebidas $(8,5 \%)$. Os setores químicos, metal-mecânicos, metalúrgicos e têxteis, que receberam grande volume dos 
investimentos realizados, foram responsáveis por 19,6\% dos empreendimentos incentivados. O emprego direto gerado pelos empreendimentos incentivados foi mais expressivo em 1998 (12.278), oscilou bastante no período, mas entre 1996 e 2004 manteve-se em determinado patamar nunca inferior a 7 mil postos anuais. Contudo, este valor caiu nos dois últimos anos analisados (4.552 e 5.400), ficando bem abaixo da média do período (8.181). Os setores que mais geraram emprego foram de produtos alimentares $(16,4 \%)$, materiais plásticos $(12,8 \%)$, bebidas $(8,8 \%)$, minerais não-metálicos $(8,6 \%)$, têxteis $(8,4 \%)$, metalúrgicos $(8,2 \%)$ e calçados/couro $(7,9 \%)$.

De acordo com os dados da RAIS/MTE, o número de estabelecimentos industriais em atividade no Estado de Pernambuco só não cresceu, entre 1995 e 2005, no setor de materiais de transporte. Os setores têxteis, mecânicos, de minerais não-metálicos, produtos alimentícios e bebidas, papel e gráfica e metalúrgicos tiveram os melhores desempenhos, sendo alguns destes setores os que mais tiveram projetos incentivados pelo Prodepe, o que sinaliza uma relação positiva entre o aumento no número de estabelecimentos industriais no Estado e a concessão de incentivos. O emprego industrial caiu nos setores de materiais elétricos e de comunicação, borracha, couro e fumo e de produtos alimentícios e bebidas, apesar deste último setor ter sido o que mais gerou emprego no âmbito do Prodepe entre 1996 e 2006 (fato que pode estar relacionado à reestruturação do setor no Estado). Nos demais setores, o emprego cresceu, mas de forma menos expressiva. Os setores com melhores resultados foram os mecânicos, de calçados, metalúrgicos, madeira e mobiliário, minerais não-metálicos e químicos, alguns dos quais figuram entre os que mais geraram emprego através do Prodepe.

O cálculo do $Q L$ para os municípios pernambucanos identificou um aumento no número de municípios especializados em diversos setores da indústria, exceto nos setores têxteis e de produtos alimentícios e bebidas - apesar do aumento no número de estabelecimentos nestes últimos (isto indica o aumento da concentração espacial dos mesmos). Os setores com maior aumento nesta quantidade: borracha, couro e fumo, metalúrgicos e químicos. Dos municípios analisados, apenas $22 \%$ são especializados em gêneros dinâmicos da indústria. Em relação à distribuição espacial da indústria, o número de municípios especializados cresceu em todas as mesorregiões do Estado, principalmente no Sertão Pernambucano e na Região do São Francisco; todavia, este aumento ocorreu de forma bastante restrita. Em relação ao perfil industrial pernambucano, dos municípios analisados pode-se destacar que, na região do São Francisco, 35\% são especializados na produção de alimentos e bebidas e $15 \%$ em minerais nãometálicos; no Sertão, $21 \%$ são especializados na produção de minerais nãometálicos e 12,9\% em extração mineral; no Agreste, $16,7 \%$ em produtos têxteis e $16,7 \%$ em madeira e mobiliário; na Zona da Mata, 28,8\% em produtos 
alimentícios e bebidas e 17,5\% em minerais não-metálicos; e na RMR há maior nível de diversificação, principalmente em gêneros dinâmicos da indústria $(14,3 \%$ química, $12,7 \%$ metalúrgica, 7,9\% mecânica, 7,9\% materiais elétricos e de comunicações, 6,3\% materiais de transporte). Em geral, o número de municípios especializados nestes setores "característicos" de cada região aumentou no período, com exceção dos setores de produtos alimentícios e bebidas na Zona da Mata.

\subsubsection{Sergipe}

Os dados relativos ao PSDI, fornecidos pela Companhia de Desenvolvimento Industrial e de Recursos Minerais de Sergipe (Codise), demonstram que no período de vigência do programa, 1991-2006, ${ }^{11} 360$ projetos foram incentivados, gerando 25.876 empregos diretos no Estado. Do total de projetos incentivados e cadastrados na Codise no período analisado, $60 \%$ estão implantados, $13 \%$ em implantação, $12 \%$ fechados, e 15\% em outra situação (não informada ou não visitada). Aproximadamente 53\% dos projetos incentivados foram realizados na Grande Aracaju, 12\% na região de Estância, 5\% na região do Baixo Cotinguiba e 5\% em Tobias Barreto. Os 25\% restantes encontram-se mais dispersos pelo Estado. O número de empresas incentivadas manteve-se próximo à média do período (45) em todos os anos analisados, sendo que 2003 foi o ano mais expressivo (57 projetos). As empresas beneficiadas pertenciam principalmente aos setores de alimentos $(11,7 \%)$, confecções $(11,1 \%)$, móveis e estofados $(8,6 \%)$, minerais não-metálicos $(8,3 \%)$, produtos químicos $(8,1 \%)$, têxteis $(6,1 \%)$, bebidas $(5,8 \%)$, laticínios (5\%) e embalagens $(4,2 \%)$. Não foram fornecidos dados relativos ao emprego gerado por ano, mas se dividirmos o total de emprego gerado no período (25.876) pela quantidade de anos analisados (16), temos uma média de 1.617 empregos diretos gerados por ano. Os setores incentivados que mais geraram emprego foram: têxteis $(13,1 \%)$, confecções $(12,6 \%)$, alimentos $(12,7 \%)$, aquicultura $(12,7 \%)$, bebidas $(6,2 \%)$, produtos químicos $(5,7 \%)$, calçados $(4,8 \%)$, móveis e estofados $(4,8 \%)$, embalagens $(4,1 \%)$ e minerais não-metálicos $(4,1 \%)$.

Em relação ao comportamento do número de estabelecimentos industriais em atividade no Estado de Sergipe, entre 1995 e 2005, pode-se observar um aumento em todos os setores da indústria de transformação, exceto no setor de materiais de transporte. Dois gêneros dinâmicos tiveram aumento significativo materiais elétricos e de comunicações e mecânica -, seguidos dos setores de papel e gráfica e de calçados. Também figuram entre os setores que mais aumentaram a quantidade de estabelecimentos os setores de minerais não-metálicos, químicos e de alimentos e bebidas, os quais receberam parcela significativa dos incentivos no período analisado (aproximadamente 60,3\% das empresas incentivadas pertencem

(11) Os dados referentes ao período entre 1991 e 1999 estão agregados. 
a estes setores). O emprego cresceu em todos os gêneros industriais, principalmente nos dinâmicos (o emprego mais que triplicou), apesar destes ainda representarem apenas $15,7 \%$ do total estadual. Os setores com melhor desempenho foram os mecânicos, de materiais elétricos e de comunicações, produtos químicos, calçados e metalúrgicos. Alguns dos setores incentivados que mais geraram emprego no âmbito do PSDI (alimentos, bebidas, têxteis, confecções, madeira e mobiliário), contudo, tiveram crescimento menos expressivo de acordo com os dados da RAIS/MTE.

No caso de SE, o cálculo do $Q L$ identificou um aumento no número de municípios especializados em todos os setores industriais, exceto na indústria mecânica. $\mathrm{O}$ número de municípios especializados na produção calçadista ainda é pequeno (6), mas cresceu bastante no período analisado. Os setores que concentraram o maior número de empresas incentivadas (alimentos, bebidas, têxteis, confecções, químicos, madeira e mobiliário) tiveram um desempenho menos expressivo e, embora alguns gêneros dinâmicos tenham tido bom resultado em relação ao emprego e ao número de estabelecimentos em atividade no período, o percentual de municípios especializados nos mesmos caiu (de 22,1\% em 1995 para 20,5\% em 2005), o que indica que os esforços relativos à desconcentração destes gêneros industriais não alcançaram resultados positivos. Em relação à distribuição espacial da indústria, o número de municípios especializados aumentou em todas as mesorregiões do Estado. O Leste Sergipano (engloba Grande Aracaju, Estância, Boquim, Propriá, Cotinguiba, Japaratuba e Baixo Cotinguiba) teve desempenho mais baixo, o que pode ser explicado pela redução do número de municípios especializados na microrregião de Estância, apesar desta ter sido a segunda maior beneficiada pelo PSDI. Nas demais regiões observa-se um movimento positivo, ainda tímido, mas que sinaliza o esforço de interiorização da indústria no Estado.

\subsection{Considerações finais}

Entre 1995 e 2005, tanto para a região Nordeste quanto para os Estados individualmente, houve um aumento no número de estabelecimentos e do emprego industriais. Em relação ao número de estabelecimentos, RN, PI e CE tiveram os melhores desempenhos e PB o desempenho menos expressivo. Já em relação ao emprego industrial, CE e SE alcançaram as primeiras posições e PE teve o pior desempenho. $\mathrm{O} \mathrm{CE}$ foi o único Estado que figurou entre os primeiros colocados nas duas situações.

Analisando os dados dos programas estaduais fornecidos por seis dos nove Estados nordestinos (empresas incentivadas, emprego gerado, localização e finalidade dos projetos), em conjunto com os dados da RAIS/MTE citados anteriormente, foi possível observar uma relação positiva, ainda que não muito 
significativa, entre o comportamento do emprego industrial e a concessão de incentivos fiscais, visto que, em geral, os setores com maiores taxas de variação no emprego entre 1995 e 2005 foram os principais beneficiados pelos programas estaduais. ${ }^{12}$ Entretanto, no que diz respeito à reestruturação da indústria local, não foi possível observar avanços significativos, pois o percentual de municípios especializados em gêneros dinâmicos da indústria ainda é relativamente baixo $(17,8 \%)$, apesar de alguns destes setores terem apresentado taxas de variação positivas no período. Além disso, os setores que mais tiveram projetos incentivados pertenciam aos gêneros tradicionais da indústria (alimentos e bebidas, têxteis e confecções, calçados, minerais não-metálicos), fato que não reflete a preocupação implícita nos programas estaduais em relação à diversificação da indústria local (concessão prioritária de incentivos a investimentos em projetos de alto valor tecnológico). A parcela de incentivos aplicada nos gêneros dinâmicos concentrou-se nos setores de produtos químicos, materiais plásticos, mecânicos e metalúrgicos, principalmente em CE e PE.

O número de municípios especializados em determinados segmentos industriais fora das áreas mais desenvolvidas da região Nordeste cresceu, o que também pode estar relacionado aos programas estaduais, visto que muitos deles estimulam a desconcentração da indústria ao fornecerem maiores incentivos para empreendimentos que se instalem em áreas menos desenvolvidas do Estado. Entretanto, este ainda é um movimento limitado. São as regiões metropolitanas as principais responsáveis pela dinâmica industrial da região e, apesar da existência de maiores benefícios para projetos localizados no interior, a quantidade de empreendimentos incentivados concentra-se em suas áreas mais dinâmicas.

De forma geral, os programas estaduais de incentivo à indústria, baseados na concessão de incentivos fiscais, parecem, em alguma medida, auxiliar a dinâmica econômica estadual e, consequentemente, da região. Contudo, como os incentivos não são os únicos fatores que influenciam as decisões de investimento dos agentes privados, a maior parte dos empreendimentos que decidem se instalar no Nordeste, ainda que considerem os incentivos oferecidos, concentra-se 1) nas áreas mais desenvolvidas de seus Estados, que possuem melhor infraestrutura de transporte, comunicações e financeira, além de trabalhadores com maiores níveis de qualificação, etc., fatores essenciais para o bom funcionamento dos mesmos, e 2) em setores já estabelecidos na região, o que pode estar contribuindo para aumentar o custo fiscal envolvido nas operações realizadas, bem como pode limitar os impactos das políticas. Este fato evidencia a necessidade de pensar no desenvolvimento como um projeto mais amplo, que englobe a melhoria de aspectos econômicos e sociais da região/Estados, visto que ao disponibilizar têxtil no PI

(12) Ou, pelo menos, os setores incentivados não deixaram de crescer, única exceção feita à indústria 
melhor infraestrutura logística e de mão-de-obra (qualificação e treinamento de trabalhadores), o Estado/região ganha um diferencial em relação à atratividade de novas indústrias.

\section{Conclusões}

O processo de desenvolvimento brasileiro sempre apresentou forte caráter regional. As primeiras atividades econômicas aqui desenvolvidas (cana-de-açúcar, mineração, café, etc.) beneficiaram determinadas regiões, que funcionavam como arquipélagos econômicos articulados aos mercados consumidores dos países centrais. Esta característica também pode ser observada - é claro que em menor intensidade - no processo de desenvolvimento recente da economia brasileira: mesmo no período de integração do mercado nacional, a dinâmica de crescimento das regiões brasileiras permaneceu bastante diferenciada. Além disto, este processo de desenvolvimento contou com intensa participação do Governo Federal, enquanto elaborador e implementador de importantes planos econômicos, como forma de estimular a economia nacional, mas sem maiores preocupações em relação à diminuição das disparidades de renda e pobreza existentes entre as regiões brasileiras, que continuaram a ser uma constante nacional.

Isso não significa que a questão regional tenha sido totalmente ignorada no período. A partir da década de 1960 o governo passou a utilizar, através das Superintendências Regionais de Desenvolvimento (Sudene, Sudam, etc.), diversos instrumentos para estimular as regiões menos desenvolvidas do país - CentroOeste, Norte e Nordeste -, alcançando resultados positivos como, por exemplo, a consolidação do parque industrial da região Nordeste. Todavia, como estas medidas não constituíam o objetivo principal da política econômica nacional, seus resultados foram limitados, no sentido de que os benefícios ocorridos nas regiões menos desenvolvidas do país acabaram por se concentrar em suas áreas mais dinâmicas, além dos investimentos serem bastante complementares à estrutura da região mais desenvolvida do país (Sudeste). A partir da década de 1980, com a crise da dívida externa e, mais tarde, com a adoção das políticas neoliberais pelo governo brasileiro, o papel interventor do Estado foi bastante comprometido, resultando na diminuição da participação direta deste na economia, inclusive no que diz respeito ao planejamento regional. ${ }^{13}$

(13) Os principais instrumentos de estímulo à dinâmica das regiões menos desenvolvidas do país (Centro-Oeste, Norte e Nordeste) foram os Fundos Constitucionais de Financiamento e as Transferências Constitucionais (FPE e FPM, principalmente). De fato, estes instrumentos foram bastante utilizados pelos governos estaduais na década de 1990 e, em muitos casos, constituíram a principal fonte de estímulo à economia local. Contudo, não se pode deixar de destacar que houve significativa redução da intervenção estatal no período, principalmente em relação à melhoria da infraestrutura física e social nestas regiões. 
Em resposta a esta mudança no papel do governo central e como forma de estimular as economias locais, os governos estaduais, em praticamente todas as regiões do país, passaram a elaborar seus próprios programas de desenvolvimento, os quais tinham por objetivo impulsionar a indústria local (devido aos seus possíveis efeitos de encadeamento). Tais programas tinham como instrumento de incentivo à iniciativa privada a concessão de benefícios fiscais relativos ao ICMS - principal imposto sobre o valor adicionado nacional, de competência estadual. O objetivo destes programas é influenciar as decisões de investimento do setor privado (criar mais um fator de atratividade local), com o intuito de gerar novos postos de trabalho, adensar as cadeias produtivas locais e estimular o processo de interiorização da indústria. À medida que os objetivos da política econômica nacional intensificavam-se no sentido de consolidar a estabilidade viabilizada pelo Plano real, a utilização destes instrumentos se intensificou, estimulando a chamada guerra fiscal.

No caso da região Nordeste, a análise dos dados referentes aos programas de incentivos de seis Estados (PI, CE, RN, PB, PE e SE) no período 1994/2006 mostra que, em geral, os setores que mais receberam incentivos, ou seja, que tiveram maior número de empresas incentivadas, foram aqueles que já têm certa tradição no Estado. Isto não quer dizer que setores não consolidados não receberam incentivos, mas sim demonstra que a participação destes setores nos programas ainda é limitada (PE, CE e SE foram os Estados que mais avançaram nesta área). O mesmo pode ser observado em relação à localização dos empreendimentos incentivados: apesar da instalação de indústrias fora das áreas mais dinâmicas destes Estados, o maior percentual de empreendimentos beneficiados pelos programas está localizado em suas regiões metropolitanas. Estas duas características indicam que o nível de discricionariedade dos programas estaduais na região Nordeste do Brasil não é elevado, fato que pode se refletir em um elevado grau de redundância dos incentivos concedidos e em um relativo desperdício de recursos públicos (incentivos redundantes poderiam ser aplicados em outras áreas).

Além disso, os dados dos programas estaduais foram analisados em conjunto com os dados da RAIS/MTE relativos ao emprego e ao número de estabelecimentos industriais em atividade na região Nordeste. O objetivo era avaliar se há alguma relação entre o crescimento do emprego (uma das principais metas dos programas estaduais) e da quantidade de estabelecimentos juntamente com a concessão de incentivos fiscais. De forma geral, os setores que mais receberam incentivos tiveram bom desempenho nestes dois indicadores entre 1995 e 2005, o que pode indicar uma relação positiva entre os programas estaduais e o crescimento da indústria na região Nordeste, bem como a receptividade do setor 
privado à política industrial estadual, apesar de todos os custos envolvidos nestes tipos de programa.

Estes resultados indicam que, possivelmente, os benefícios fiscais têm colaborado para atrair empresas para a região Nordeste ainda que a um elevado custo fiscal. Entretanto, os maiores beneficiados pelos programas são os setores já consolidados na região e que dispõem de toda a infraestrutura necessária ao seu funcionamento (o incentivo está funcionando como diferencial de atratividade principalmente nos setores em que a região Nordeste possui maiores vantagens competitivas). Consequentemente, devido às características industriais desta região, os setores que mais receberam incentivos pertencem aos gêneros tradicionais da indústria (exceto em PE e no $\mathrm{CE}$ ), o que pode estar potencializando a geração de emprego no âmbito dos programas.

Estes fatos evidenciam que os programas estaduais baseados em incentivos fiscais e financeiros não são capazes, por si só, de alterar significativamente a dinâmica econômica local, visto que os incentivos não são os únicos fatores determinantes da atratividade local. ${ }^{14}$ Assim, torna-se clara a necessidade da adoção de outras medidas, de caráter mais duradouro e estrutural (investimentos em educação, qualificação profissional, infraestrutura física e social, etc.), para estimular as áreas menos dinâmicas do Estado/região/país, criando um ambiente econômico e institucional mais favorável ao desenvolvimento de atividades produtivas.

Em suma, o desenvolvimento regional numa perspectiva nacional necessita de uma profunda reformulação dos atuais instrumentos. É preciso articular a política de desenvolvimento regional a políticas de outras áreas, e identificar as oportunidades de investimentos numa perspectiva mais ampla, tanto setorial quanto espacial, sem desconsiderar os avanços necessários também nas áreas sociais, fator fundamental para impulsionar a dinâmica econômica local em um cenário econômico, nacional e internacional, que exige cada vez mais maleabilidade de seus produtores. A ausência do governo central no planejamento regional não leva ao desaparecimento de programas de desenvolvimento regional, e sim à sua elaboração em outros níveis, nem sempre com os resultados mais favoráveis.

\section{Referências bibliográficas}

DINIZ, C. C. A questão regional e as políticas governamentais no Brasil. Belo Horizonte: Cedeplar, 2001. (Texto para Discussão, n. 159). Disponível em: https://www.cedeplar.ufmg.br.

(14) Os incentivos fiscais não são capazes de construir bases permanentes e sustentáveis para o desenvolvimento (política Second Best). 
DULCI, O. S. Guerra fiscal, desenvolvimento desigual e relações federativas no Brasil. Revista de Sociologia e Política. Curitiba, n. 18, p. 95-107, jun. 2002. Disponível em: http://www.scielo.br.

FERREIRA, G. D. Políticas estaduais de desenvolvimento e guerra fiscal. 2005. 204 p. Dissertação (Mestrado em Economia) - Universidade Estadual de Campinas, Campinas, 2005.

LAGEMANN, E. O federalismo fiscal brasileiro em questão. In: AFFONSO, Rui de Britto Álvares; SILVA, Pedro Luiz Barros. A Federação em perspectiva - ensaios selecionados. São Paulo: Fundap. 1995.

LIMA, A. C. C. Políticas de Desenvolvimento Regional no Brasil: mecanismos nacionais e estaduais - o caso do Nordeste. 2008. 176p. Dissertação (Mestrado em Economia) Universidade Federal de Pernambuco, Recife, 2008.

OLIVEIRA, F. A. de. A lógica das reformas: a evolução do sistema tributário (19662002). In: PINTO, M. P. A.; BIASOTO JÚNIOR, G. (Org.). Política fiscal $e$ desenvolvimento no Brasil. Campinas: Editora da Unicamp, 2006.

PRADO, S. A guerra fiscal e políticas de desenvolvimento estadual no Brasil. Economia e Sociedade, Campinas, v. 13, p. 1-40, dez. 1999.

PRADO, S.; CAVALCANTI, C. E. G. A guerra fiscal no Brasil. São Paulo: Fundap: Fapesp; Brasília: Ipea, 2000.

ROCHA, A. G. T.; AMARAL FILHO, J. do; MELO, M. A. C. de. As políticas de incentivos fiscais dos Estados da Bahia, Ceará e Pernambuco: algumas evidências institucionais. In: BERNAL, M. C. C. (Coord.). A economia do Nordeste na fase contemporânea. Fortaleza: BNB; UFC edições, 2006. (Coleção Livro Acadêmico).

SOARES, F. de A.; SANTOS, S. M. dos; TENÓRIO, J. N. B.; FRAGOSO, S. N. Interiorização e reestruturação da indústria do Ceará no final do século XX. Revista Econômica do Nordeste, Fortaleza, v. 38, n. 1, p. 86-102, jan./mar. 2007.

VARSANO, R. A guerra fiscal do ICMS: quem ganha e quem perde. Rio de Janeiro: Ipea, 1997. (Texto para Discussão, n. 500). Disponível em: http://www.ipea.gov.br.

WELLS JR., L. T.; ALLEN, N. J. Tax holidays to attract foreign direct investments lessons from two experiments. In: WELLS Jr. et al. Using tax incentives to compete for foreign investment. Are they worth the costs? Washington, DC: World Bank, 2001. (Occasional Paper, n. 15). 


\section{Apêndice}

Tabela A.1

Região Nordeste - Indústria de Transformação e Extrativa Mineral - Estabelecimentos em Atividade - 1995 e 2005

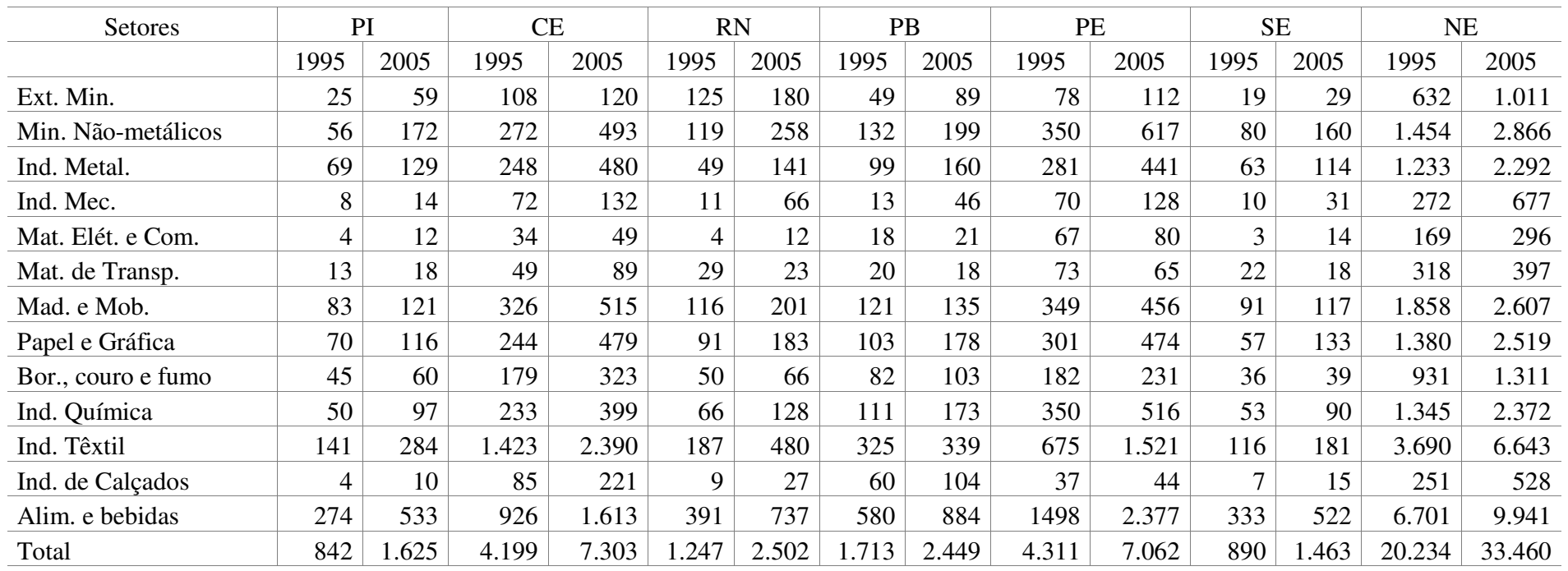

Fonte: RAIS/MTE. 
Tabela A.2

Região Nordeste - Indústria de Transformação e Extrativa Mineral - Emprego - 1995 e 2005

\begin{tabular}{|c|c|c|c|c|c|c|c|c|c|c|c|c|c|c|}
\hline \multirow[t]{2}{*}{ Setores } & \multicolumn{2}{|c|}{ PI } & \multicolumn{2}{|c|}{$\mathrm{CE}$} & \multicolumn{2}{|c|}{$\mathrm{RN}$} & \multicolumn{2}{|c|}{$\mathrm{PB}$} & \multicolumn{2}{|c|}{$\mathrm{PE}$} & \multicolumn{2}{|c|}{ SE } & \multicolumn{2}{|c|}{$\mathrm{NE}$} \\
\hline & 1995 & 2005 & 1995 & 2005 & 1995 & 2005 & 1995 & 2005 & 1995 & 2005 & 1995 & 2005 & 1995 & 2005 \\
\hline Ext. Min. & 2071 & 843 & 2.947 & 1.816 & 5.006 & 6.017 & 795 & 1.407 & 1.577 & 1.703 & 923 & 2.054 & 20.473 & 23.764 \\
\hline Min. Não-metálicos & 1382 & 3177 & 3.934 & 7.495 & 2.372 & 4.506 & 2.810 & 4.421 & 8.021 & 11.179 & 1.967 & 3.608 & 29.357 & 51.746 \\
\hline Ind. Metal. & 478 & 843 & 5.636 & 7.601 & 261 & 1.182 & 981 & 1.572 & 5.921 & 8.429 & 494 & 1.150 & 24.493 & 33.925 \\
\hline Ind. Mec. & 22 & 129 & 1.260 & 2.776 & 397 & 1.366 & 177 & 476 & 1.499 & 2.194 & 40 & 1.016 & 5.501 & 13.788 \\
\hline Mat. Elét. e Com. & 31 & 113 & 1.385 & 2.049 & 1 & 123 & 394 & 296 & 5.703 & 4.512 & 17 & 204 & 8.361 & 10.856 \\
\hline Mat. de Transp. & 143 & 756 & 660 & 2.212 & 136 & 219 & 108 & 105 & 1.667 & 1.857 & 424 & 615 & 4.344 & 13.281 \\
\hline Mad. e Mob. & 1246 & 1276 & 3.320 & 5.619 & 830 & 1.368 & 609 & 981 & 3.023 & 4.225 & 744 & 894 & 19.637 & 24.809 \\
\hline Papel e Gráfica & 805 & 890 & 3.827 & 5.862 & 1.102 & 1.899 & 1.781 & 2.397 & 6.036 & 7.435 & 647 & 1.143 & 23.611 & 29.753 \\
\hline Bor., couro e fumo & 1260 & 839 & 2.538 & 6.009 & 570 & 522 & 1.395 & 3.319 & 2.787 & 2.748 & 456 & 859 & 15.487 & 23.899 \\
\hline Ind. Química & 927 & 1700 & 5.647 & 9.284 & 1.246 & 2.969 & 1.884 & 3.132 & 9.781 & 13.157 & 424 & 2.247 & 40.400 & 60.822 \\
\hline Ind. Têxtil & 4656 & 3371 & 34.574 & 52.449 & 9.316 & 20.722 & 7.700 & 11.976 & 18.067 & 18.365 & 6.248 & 6.588 & 93.073 & 132.659 \\
\hline Ind. de Calçados & 28 & 52 & 6.339 & 44.268 & 164 & 1.835 & 5.688 & 8.461 & 1.222 & 1.776 & 743 & 2.108 & 14.477 & 81.597 \\
\hline Alim. e bebidas & 3728 & 8052 & 33.361 & 35.641 & 14.103 & 15.851 & 16.021 & 18.093 & 85.262 & 84.476 & 6.308 & 10.841 & 252.176 & 300.006 \\
\hline Total & 16.777 & 22.041 & 105.428 & 183.081 & 35.504 & 58.579 & 40.343 & 56.636 & 150.566 & 162.056 & 19.435 & 33.327 & 551.390 & 800.905 \\
\hline
\end{tabular}


Tabela A.3

Região Nordeste - Padrão de especialização municipal (Quociente Locacional) - 1995 e 2005

\begin{tabular}{l|r|r|r|r|r|r|r|r|r|r|r|r|r|}
\hline \multicolumn{1}{c|}{ Setores } & \multicolumn{2}{|c|}{ PI } & \multicolumn{2}{|c|}{ CE } & \multicolumn{2}{c|}{ PB } & \multicolumn{2}{c}{ PE } & \multicolumn{2}{c}{ SE } \\
\hline & 1995 & 2005 & 1995 & 2005 & 1995 & 2005 & 1995 & 2005 & 1995 & 2005 & 1995 & 2005 \\
\hline Extr. Min. & 7 & 14 & 24 & 30 & 17 & 21 & 16 & 25 & 20 & 29 & 3 & 6 \\
\hline Min. Não-metálicos & 10 & 29 & 40 & 59 & 23 & 25 & 24 & 41 & 37 & 48 & 11 & 18 \\
\hline Ind. Metalúrgica & 5 & 7 & 7 & 15 & 6 & 4 & 10 & 12 & 12 & 22 & 6 & 11 \\
\hline Ind. Mecânica & 2 & 2 & 8 & 8 & 3 & 5 & 2 & 5 & 7 & 10 & 3 & 2 \\
\hline Mat. Elétricos e de Com. & 1 & 2 & 2 & 3 & 1 & 3 & 3 & 3 & 5 & 7 & 1 & 2 \\
\hline Mat. de Trans. & 2 & 1 & 2 & 7 & 7 & 8 & 6 & 5 & 9 & 10 & 2 & 2 \\
\hline Madeira e Mobiliário & 9 & 12 & 27 & 46 & 9 & 12 & 15 & 14 & 38 & 44 & 8 & 9 \\
\hline Papel e Gráfica & 4 & 6 & 14 & 14 & 5 & 6 & 5 & 9 & 13 & 14 & 3 & 3 \\
\hline Borracha, couro e fumo & 5 & 4 & 6 & 9 & 4 & 7 & 9 & 10 & 13 & 24 & 4 & 6 \\
\hline Ind. Química & 5 & 8 & 12 & 19 & 7 & 12 & 10 & 14 & 18 & 27 & 5 & 6 \\
\hline Ind. Têxtil & 10 & 6 & 21 & 19 & 15 & 24 & 16 & 14 & 33 & 30 & 10 & 12 \\
\hline Ind. de Calçados & 1 & 3 & 6 & 23 & 2 & 6 & 10 & 11 & 7 & 7 & 2 & 6 \\
\hline Alim. e bebidas & 18 & 19 & 56 & 68 & 25 & 52 & 47 & 70 & 74 & 73 & 19 & 29 \\
\hline Total & 79 & 113 & 225 & 320 & 124 & 185 & 173 & 233 & 286 & 345 & 77 & 112 \\
\hline
\end{tabular}

Elaboração própria a partir de dados da RAIS/MTE. 